\title{
Holy cows or cash cows? The economic return to livestock in rural India*
}

\author{
Orazio Attanasio and Britta Augsburg
}

April 2014. Revised March 2016.

Running Title: Holy cows

Key Words: Investment, Profits, Livestock, India

JEL Classification: E21, M4, O12, Q1, Q12

Contact information: Britta Augsburg (corresponding author), The Institute for Fiscal Studies, 7 Ridgmount Street, London WC1E 7AE, UK, phone: 0044 (0)20 7291 4800, fax: 0044 (0)20 7291 4780, britta_a@ifs.org.uk; Orazio Attanasio, University College London, IFS, NBER and BREAD, o.attanasio@ucl.ac.uk.

\footnotetext{
${ }^{*}$ We would like to thank David Phillips for suggesting the title of this note. This research was partly financed with funds from ESRC grants RES-000-22-3461, RES-167-25-0124 and RES-051-27-0135 and from ERC grant 249612 on $\{\backslash$ textquoteleft $\}$ Exiting Long Run Poverty: The determinants of asset accumulation in developing countries'. All errors and opinions are our own.
} 


\begin{abstract}
This paper revisits recent claims that poor households owning cattle in developing countries settings do not behave according to the tenets of capitalism. We point out that the discussion was based on evidence from one single year only, while cows and buffaloes are assets whose return varies through time. In drought years, when fodder is scarce and more expensive, milk production is lower and profits are low. In non-drought years, when fodder is abundant and cheaper, milk production is higher and profits can be considerably higher. Therefore, the return on cows and buffaloes, like that of many stocks traded on Wall Street, is positive in some years and negative in others. The fact that in a given year the observed return on a risky asset is negative could certainly not be used as a contradiction of 'one of the basic tenets of capitalism'. We report evidence from three years of data on the return on cows and buffaloes in the district of Anantapur and show that in one of the three years returns are very high, while in drought years they are predominantly negative.
\end{abstract}




\section{Introduction}

Income in rural villages in developing countries is risky. Large observed fluctuations are driven by a variety of factors, with weather playing a large role. Rosenzweig and Udry (2013) point out that many investments in agricultural production exhibit state-dependent returns. While they refer to the returns to planting a variety of crops, similar evidence exists for many other investments. Therefore, it should not be surprising that the returns to one of the most important assets in rural India, namely cows and buffaloes, exhibit large fluctuations. If an important part of the variability of returns is linked to aggregate shocks (such as the weather), it would be difficult to assess the mean return of a given asset considering a single cross-section of data.

In a recent paper, Anagol, Etang and Karlan $(2013)^{1}$ (AEK henceforth) have called attention to an apparent puzzle. According to these authors, the fact that many households in India own cows and buffaloes contradicts one of the basic tenets of capitalism. The argument is quite simple. The authors consider the income generated by these assets (mainly the revenue obtained from selling the milk that is produced but also other outputs, such as dung) and compare it to the costs that are incurred to generate such income (mainly fodder but also health costs). Given the value of the animals, the net profit generated completely ignoring labor costs gives rise to a small positive rate of return. Once any reasonable estimate of labor costs is added to the calculation, the rate of return is a large negative number. The authors therefore conclude that the households holding this type of asset do not behave according to the tenets of capitalism. The paper has received some attention: the newspaper The Economist wrote about it and Acemoglu and Robinson (2013), who discussed it in their blog, ask: 'What could explain such irrational economic practices?'. A variety of explanations, typically appealing to religious or cultural factors, have been invoked for such

\footnotetext{
${ }^{1}$ In this study, we cite primarily AEK's 2013 NBER working paper, which reports average returns to the investment. We will also from time to time refer to their more recent 2014 and 2016 versions of the paper, where the authors switched to reporting medians along with some other smaller changes. If a reference is specific to one of these versions, we make this clear by referencing with the date of the publication; otherwise we will refer to AEK without a year.
} 
puzzling behavior.

In this study, we would like to point out to a much simpler explanation that, surprisingly, has not been mentioned in the discussions that have followed the circulation of the paper and that is fully consistent with rational behaviour on the part of Indian farmers. In computing the return on cows and buffaloes, the authors used data from a single time period. They considered 300 cows and 384 buffaloes in two districts of the region of Uttar Pradesh, India in 2007. While each individual cow and buffaloe is, arguably, a single asset, averaging across the returns of many of them in a single year does not yield the average return on cows and buffaloes. Cows and buffaloes are assets whose return varies through time. Moreover, the return on different cows and buffaloes is strongly correlated over time. In drought years, when fodder is scarce and more expensive, milk production is lower and profits are low. In non-drought years, when fodder is abundant and cheaper, milk production is higher and profits can be considerably higher. Therefore, the return on cows and buffaloes, like that of many stocks traded on Wall Street, is positive in some years and negative in others. The fact that in a given year the observed return on a risky asset is negative could certainly not be used as a contradiction of 'one of the basic tenets of capitalism'.

Our argument is consistent with the point raised by Rosenzweig and Udry (2013) on the variability and uncertainty of the returns to many agricultural investments in rural developing economies, when they state that 'studies that show the profitability of an investment or technological innovation or the return to an intervention are typically based on data from a single season in a particular locality and hence are conditional on a single realization of weather or other correlated shocks [...]. Because of weather variability and other sources of aggregate risk, the standard errors associated with the estimated coefficients substantially overstate the precision of the return estimate.'

In this paper, we show that the worry articulated by Rosenzweig and Udry (2013) is salient for the context studied by AEK. We present evidence (based on detailed data from the district of Anantapur) that, while for some time periods the return to cows and buffaloes is low or 
negative, in other periods it is positive and possibly high.

We have detailed data on about 1,000 households in 60 villages in the district of Anantapur in Andhra Pradesh. For these households, we have detailed data on animal ownership and, if they own a cow and/or buffalo, detailed data on milk production, and milk prices, as well as costs associated with generating this income, including health costs, fodder costs and so on. Our data are in some respects less and in others more detailed than those used by AEK. For example, we have milk yield information only for the so-called full and lean lactation periods, whereas AEK collected information on 0-3, 3-6, 6-9 and 9-10 months after calving. On the other hand, we have more detailed information on the fraction of milk produced that is consumed within the household, and on losses other than veterinarian fees that the household incurs when the animal falls ill. But the main difference and advantage relative to AEK's data is that we have data on three years, 2008, 2009 and 2012. Moreover, conditions in those three years are very different. Two of them were drought years, while the third year was a good year in terms of rain and, therefore, agriculture incomes. Whilst three years are probably not enough to compute an estimate of the 'average' return on cows and buffaloes that is precise enough to be meaningful, the fact that we have both 'good' and 'bad' years can be used to illustrate the point that what AEK call the 'average' return changes dramatically from one year to the next.

For the drought years, we obtain results that are remarkably similar to those obtained by AEK: the return on cows and buffaloes is a small positive number when ignoring labor costs and a large negative number when taking them into account. This fact was noted in Augsburg (2011). However, when we consider the non-drought year, the return is a high positive number. This result is mainly driven by two factors. First, fodder prices are considerably lower. Second, milk production, possibly driven by the better nutrition the animals can enjoy, is remarkably higher.

The conclusion we draw from our simple exercise is not, necessarily, that the asset-holding behavior of poor Indian farmers is optimal. Cows and buffaloes are certainly risky assets. And 
the information we have on their returns is not sufficient to fully characterize their stochastic properties. Moreover, optimal decisions will depend not only on the distribution of returns but also on the availability of insurance mechanisms that could allow the diversification of the risks implied by certain investments. Having said that, however, we think that the statement that 'the continued existence of cows contradicts one of the basic tenets of capitalism' is unjustified.

The rest of this study is organized as follows. Section 2 describes our data and Section 3 presents our computation of returns and compares them to the results obtained by AEK. Section 4 concludes.

\section{Data}

The district of Anantapur is the largest of the 13 districts of Andhra Pradesh, in South India and lies in an area that is characterized by scarce rainfall, poor soil conditions and frequent droughts. The data we use were collected as part of an evaluation of a product offered by the microfinance institution BASIX. The product included a loan for investment into a buffaloe or cow to start the production of dairy products. Clients could further opt into life insurance for the animal as well as access to business development services tailored to cattle rearing. The surveys conducted covered 64 villages in which BASIX was operating at the time of the first survey round or that BASIX planned to expand into in the near future. Accordingly, the households selected into the survey were either BASIX clients or potential clients and were among the poorest households in the study district.

A total of 1,041 households were selected at the time of the first survey round in 2008 and extensive information on a wide range of variables was collected. This included information on livestock ownership and detailed data on milk production and use, on costs connected with dairy production and, more generally, about household income, consumption and socioeconomic variables. Table A1 in Appendix A gives some descriptive statistics of cattle-owning 
households in our first survey year. To briefly summarize, the average household is headed by an uneducated, married male, 44 years of age. The average household has five members, about two of them female and at least one younger than 16. A bit more than $40 \%$ of the households belong to the backward caste, $37 \%$ to the forward caste and $10 \%$ to the scheduled caste. The primary activity of $58 \%$ of the households is agricultural labor and $34 \%$ are farmers, implying that at least $92 \%$ of all the respondent households are dependent on income from agriculture.

The interested reader is referred to Augsburg (2009) for more details on the survey households as well as the survey design and evaluation results from the first survey round.

The same households were contacted again in 2009. Of the original 1,041 households, 951 were re-interviewed with very similar survey instruments. A final survey was conducted in 2012 in which 885 households could be re-contacted.

Given the purpose of the data collections, much emphasis was given to information on livestock ownership, the income it generates, and the costs connected to the ownership and management of the animals. The surveys also contained information on subjective expectations on income, both from dairy and non dairy sources, which we have used in Attanasio and Augsburg (2016).

We present some summary statistics for the three surveys in Table $1 .^{2}$ Of the households surveyed, $61 \%$ owned livestock in 2008. This percentage goes down to $43 \%$ in 2009 and to $36 \%$ in 2012. These are quite significant drops, particularly between the first and second survey round. Two main reasons can be brought forward to explain these drops. For one, BASIX clients who took a loan for the purpose of investing in livestock were oversampled at the time of the first survey round. It is conceivable that not all of these households had the relevant skills to keep the animals over time. However, we see that BASIX clients are not more likely to reduce their animal stock than non-clients are. We show the same descriptive

\footnotetext{
${ }^{2}$ Note that all monetary values we present in this paper are adjusted for inflation and given in 2008 pricesusing figures from http://www.global-rates.com/economic-indicators/inflation/2008.aspx.
} 
statistics as presented in Table 1, for non-clients only in Table A2 in Appendix A. We further show in Tables B1 and B2 in Appendix B the rates of return we will describe and present below for the subset of non-BASIX owners only. These rates of return are very similar to those for the whole sample (especially for buffaloes, where we have a much larger sample) and the general conclusion holds. It therefore does not seem to be the case that the oversampling is driving compositional changes.

\section{[TABLE 1 ABOUT HERE]}

The second plausible explanation for the observed drop is the fact that India, and especially the state in which our study took place, was hit by a microfinance crisis in October 2010, i.e. just after the second survey round and some time before the third one. Data on households' debts and loans reveal that their access to microfinance loans, the main formal source for our study households, dropped dramatically during this period. Such loans are the main form of finance for purchasing cattle. In 2009, $80 \%$ of all study households that own cattle report that they have in the past taken a loan to pay for an animal and $62 \%$ report that they currently have a loan outstanding for an animal. While we do not have the same information for the last survey round, we do know that the number of loans taken in the period between the second and third survey rounds dropped dramatically, especially for formal loans, the main source used to buy animals. This is likely to be a main driving factor behind the observed decline in the number of households owning cattle.

At the same time, we see that households that keep their cattle do not decrease their herd size; if anything, we see a slight increase (from 3.5 in 2009 to 4.7 in 2012). As a larger herd size brings economies of scale (as shown in Gehrke and Grimm (2014)), the rates of return we present in this study might be considered upper bounds in our later survey years. The main point we make is that returns vary and we show that while in the first round of data households experience a positive return, they later experience a negative return. If the change in ownership composition introduces economies of scale, this would only make our 
conclusions stronger.

The longitudinal nature of our data makes it ideal for studying the evolution of cow ownership and investment. For instance, one could study the extent to which the purchase and sale of animals follow certain shocks, along the lines of Rosenzweig and Wolpin (1989). Modeling individual choices, however, is beyond the scope of this paper.

Given the ownership rates and the number of animals owned, we have data on 585 cows or female buffaloes in 2008, 379 in 2009 and 295 in 2012. To make our estimates comparable to those of AEK, we concentrate on households that own either only cows or only buffaloes, reducing the number of observations somewhat further. Our results are not affected by this choice. They compare to the 684 cows and buffaloes anaylzed by AEK.

Cow ownership is less common than buffaloe ownership in the district of Anantapur, which implies that our estimates for cows are based on a much smaller sample than those for buffaloes. The primary reasons for this preference are exceptionally hostile conditions for agriculture and animal husbandry, the main culprits being scarce and volatile rainfall and limited irrigation facilities, which lead to frequent droughts and scarce fodder. Buffaloes typically cope better under such conditions than cows, although they are both sensitive to heat stress and to changes in nutrition. These factors lead to less frequent breeding, which again leads to lower milk yields and hence lower returns to the investment.

Our first round of data was collected during a period of below-average temperatures and above average rains, whereas the opposite holds true for the second and third survey rounds. Table C1 in Appendix C provides district rainfall data for Anantapur over the years 20072012. ${ }^{3}$ We highlight the months during which data collections took place and indicate the important harvest periods. It can be seen that the months prior to the first survey round were characterized by close to average rainfalls, often above, whereas months prior to the following two survey rounds, included months with very low rainfall.

\begin{tabular}{llr}
\hline${ }^{3}$ Data were obtained online from the India Meteorological & Department \\
(http://www.imd.gov.in/section/hydro/distrainfall/webrain/andhra/anantapur.txt & and \\
http://archive.is/be3q, last accessed on March 30, 2014). &
\end{tabular}


AEK point out in their 2016 version that total rainfall in 2007 in their two survey districts, Lakhimpur Kheri and Sitapur, was relatively close to the long run average rainfall values. It is still worth noting though that the year 2007 seems to have been characterized by some high distress, suggesting that the 2007 average might hide important variation: both an extreme heat-wave and a cold-wave were reported in 2007, which lead to a number of deaths, some of which were in Sitapur district. ${ }^{4}$ While we do not know whether the extreme weather conditions affected the study population, it is conceivable that they might have reduced returns within the study year.

\section{Returns on livestock}

To estimate the rate of return on cows and buffaloes, we perform an exercise which is very similar to that performed by AEK and by Augsburg (2009). Although the data are very rich indeed, we need to make assumptions on a number of variables to estimate both revenues and costs. Although some assumptions are slightly different from those used by AEK because of the nature of our data, as we discuss below, these slightly different procedures do not explain the difference in the rate of profit in 2008 relative to what we get in 2009 and 2012 and to what AEK calculate. In the first year of our survey, profits are much higher than in our second and third rounds of data, when our figures are similar to those in AEK, not just in terms of total revenue but also in terms of its components.

In what follows, we first explain the way revenues and costs are imputed and how our assumptions differ from those of AEK. We then provide our estimates for each of the three years considered.

\footnotetext{
${ }^{4}$ http://nidm.gov.in/PDF/DU/2007/June/12-06-07.pdf, last accessed March 20, 2014.
} 


\subsection{Revenues and costs: assumptions}

In Table 2, we summarize the main assumptions that are needed to compute revenues and costs in our survey and how they compare to those used by AEK. We will refer to them in our description of the data below and whenever relevant for our estimations. The table also provides summary statistics for the relevant variables for all survey rounds with our data and for AEK's sample.

\section{[TABLE 2 ABOUT HERE]}

\subsubsection{Revenues}

The revenues a poor household gets from owning a cow or a female buffaloe come mainly from three sources. First and foremost, there is the milk produced, which is then either sold or consumed within the household. Second, there is the value of calves that are born following the insemination of the animal. In many cases, the farmers do not realize any revenue from the sale of the calves, ${ }^{5}$ but in some cases they do. Third, there is the revenue from the sale of dung, which can be used as fuel. Unfortunately, our data do not provide information on returns from dung sale separately, but households were asked about income from selling milk and other by-products (such as dung) combined.

We estimate revenues generated through milk production based on two components: (1) households report in the income section their yearly return from selling milk and (2) we estimate the value of home consumed milk based on (a) the amount of milk produced, (b) the price the household receives per liter of milk sold, and (c) the percentage of produced milk that members of the household consume themselves.

To estimate milk production, we use information reported by the households about the number of months for which the animals are lactating. The answers average 7.9 in 2008, 7.7

\footnotetext{
${ }^{5}$ Informal interviews with respondents revealed that it is very common to leave calves to die as the benefits of going to the market and selling the animals, or raising them until they can breed are not perceived to outweigh the costs of doing so.
} 
in 2012 and only 6.3 in 2009. These seem very different from the 10 months assumed by AEK. However, these authors later assume that there are only 265 days in a year in which milk is produced, which does not differ much from what we get from households' responses. As for the amount of milk produced, AEK split the milking cycle into four periods, where milk production peaks in the second cycle. Buffaloes, for example, produce an average 3.5 liters per day in the first period, 3.6 in the second, 2.8 in the third and 0.7 in the fourth and last part of the cycle. Our survey provides information only on two parts of the cycle: the full and the lean periods. We assume that the full period coversthree-fourth of the lactation period reported by the household and the lean period one-fourth. Our survey also contains information on the quantity of milk produced in the full and lean periods. The average number of liters produced in the full season compare roughly to the average for the first and second lactation periods of AEK and the average in the lean period compares to the average for their third and (shorter) fourth periods. Whilst we have information on average returns over the last year and last month, as well as on the number of months the animal typically provides milk and is dry, these data are not informative of whether the animal was or is dry currently. ${ }^{6}$

The second assumption we need to make to estimate the value of home-consumed milk is on the price the household would receive for the milk. Here we simply assume that they would receive the same price as they do for the milk they actually sell. For households that only consume their milk and for which we therefore do not have prices, we use village averages. ${ }^{7}$

\footnotetext{
${ }^{6}$ In addition, we unfortunately do not have information on the age of the cows and buffaloes, so we cannot produce a graph such as AEK's Figure A4, which indicates that most non-milking animals are young animals. We however know from anecdotal evidence that the majority of cows are bought by households at around 3 years old, i.e. at a time when the animal can start producing milk, and that an animal is typically sold off when it is not producing anymore. Raising calves is surprisingly uncommon in the study areas.

${ }^{7}$ We note that this assumption is a conservative one to make, potentially underestimating the value of home consumed milk. The reason for this is that it is common practice in the study area to 'water-down' milk before selling it. Given that the price of milk paid to a household typically depends on the fat percentage of the milk the price households report they are paid would reflect the lower fat percentage due to the water added. On the other hand, households report the number of liters they consume of the produced milk, i.e. non-watered down milk. Since we do not have detailed information on how much water is added to the milk before selling it, we cannot credibly adjust the price for home consumed milk and we prefer to report conservative return estimates. This issue is likely to be stronger in 2008, when testing of fat percentages was still less commonly done in the study areas (in $2008, \sim 5 \%$ of respondents reported that their milk is tested by
} 
Our average prices range from Rs 6.8 to Rs 15.0, depending on the animal type and year of study, and include the value of Rs 10 used by AEK. The variations are likely to be driven by market demand, our data showing lower prices in the 'good' year and higher prices in the 'bad' years.

Our data also provide information about households' typical income from selling milk. We report the average income in the year previous to the survey and the reported typical income in Table 3. It can be seen that typical income does vary but is more stable than realized income. Further, typical income is below last year's income in the 'good' year (2008) and above in the 'Bad' years (2009 and 2012).

\section{[TABLE 3 ABOUT HERE]}

\subsubsection{Costs}

The main source of costs is fodder. Contrary to AEK, we use fodder costs reported by the household in our returns estimates. AEK have detailed information on the amounts households spent on different types of feed. However, due to concerns of over- and underreporting, they prefer to use estimates from feeding guidelines obtained through a fodder company $^{8}$ in their $2013 \mathrm{WP}$ version and various online sources in their $2014 \mathrm{WP}$ version. Their rationale behind this practice is that these provide more conservative estimates. Given that milk yield is highly influenced by feeding, we do not consider this to be a good assumption to make, as it introduces a mismatch between fodder costs and the information on returns. We instead use information from direct questions to respondents on the amounts spent on different types of fodder and the percentage of fodder collected. By making the conservative assumption that collected fodder is priced the same as bought fodder, we impute a value to

their buyer, increasing to $\sim 80 \%$ in 2009 ; no numbers are available for 2012). Regular testing of milk reduces the incentive to add water to the milk.

${ }^{8}$ In the 2013 WP version, they use the so-called Kisan Company methodology, to validate their fodder costs (Kisan is a company that produces feed). When calculating fodder costs using this method, AEK find that both cows and buffaloes are generally profitable. 
the collected fodder. As can be seen in Table 2, the cost of fodder varies considerably over the years in our sample.

We also have data on the average cost per vet visit, which include the cost of insemination, and the average additional cost incurred per vet visit . AEK separate these costs. Finally, unlike AEK, we have information on additional costs the household incurs from the animal falling ill (and possibly dying).

Similarly to AEK, we have direct data on the value of livestock (both cows and buffaloes) in the villages in each of the years of our survey and use those to compute the rates of return. One drawback of our data, however, is that we do not have the age of the animals owned. We are therefore not able to estimate the appreciation/depreciation of animal value over the year. This is, however, a relatively minor source of costs, so the neglect is unlikely to introduce significant biases. We nevertheless report our estimates without this cost and using the averages reported by AEK.

The final cost component relates to labor. Similarly to AEK, our third survey round asks about the hours spent caring for the animal per day. We follow their approach of assuming that time spent on the sample animal is equal to the total hours spent on animals owned divided by the number of animals owned. Our sample households spend on average of 3.1 hours taking care of their animals, which is closely in line with the average 3.17 hours caretaking in AEK.

We obtain our estimates of the cost per hour of labor from village-specificlevel surveys conducted in each of the three survey years. The procedure we follow is similar to that used by AEK and we report our averages in Table 4. While we have wages split for male and female workers, only our 2012 survey has information on wages for minors. . Given that respondent report that minors share the work of taking care of animals to an equal extent, we estimate the wage for minors based on AEK's adult to minor wage ratio. We then proceed as AEK and take the average of the wages for adults and for minors. 


\section{[TABLE 4 ABOUT HERE]}

\subsection{Estimates of rates of return}

Tables 5 and 6 report our computations for the average and median rate of return on holding cows and buffaloes respectively and compare them to the figures reported by AEK. ${ }^{9}$ Each table reports four columns: the first three refer to our surveys in 2008, 2009 and 2012, while the last one reports the data in AEK for comparison. ${ }^{10}$ The first panel of the tables refers to the value of the animals, the second to revenues, the third to costs and the fourth to profits. The last two panels report rates of return, first using only our data and assumptions and then using information on appreciation/depreciation and labor costs from AEK and excluding other losses due to sick animals (in line with AEK).

\section{[TABLE 5 ABOUT HERE]}

Starting with Table 5, which refers to buffaloes, we notice that the value of buffaloes is relatively stable over the first two survey years, averaging almost Rs 9,000 per animal, and then it increases in the last survey round. The values are somewhat higher than the one reported by AEK, where the average buffaloe has a value of Rs 7,171.

Turning to returns from owning a buffalo, we find that AEK's figure on the value of milk produced and dung sold at Rs 12,299 $(10,374+1,925)$, lies close to our 2012 estimate of Rs 12,352. In contrast, our survey households report a considerable lower return in 2009, which is primarily driven by a shorter lactation period in that year and an increased percentage of home consumption. In 2008, the value of milk sold and consumed is much higher, because of a longer lactation period and a higher yield during lactation. As mentioned above, our estimates for total revenue include a modest amount derived from the sale of calves, while the

\footnotetext{
${ }^{9}$ Average values for AEK are taken from the 2013 working paper version. Median rates of return are taken from the 2016 version published in this journal.

${ }^{10}$ Note that we adjust their 2007 values for inflation to make them comparable to our estimates.
} 
AEK estimates also include dung sales separately, whereas in our estimates they are included in 'value of milk and other by-products' .

Turning to costs, the second panel in Table 5 shows that the fodder cost reported by AEKs is noticeably higher than our estimates. Their households spend on average Rs 12,913 per buffaloe whereas our households spent almost Rs 5,000 in 2008, around Rs 6,000 in 2009 and around 9,000 in 2012. In the two latter survey years, we see a shift away from green fodder, which the household can often collect for no charge, which especially in 2012 seems to be driving up expenditures.

The next variables reported in Table 5 provide information on health expenditures for the animals. We first show reported expenditures with a veterinarian, which in our data include insemination costs. It can be seen that our health costs tend to be higher than the figure reported by AEK. AEK's combined vet and insemination costs in 2007 are Rs 288, while our households report combined costs of Rs 630, Rs 594 and Rs 259 in the three survey years respectively. We can further see variation in other costs incurred when the animal falls ill (information not collected by AEK), which can include death, over the study years. These additional costs are relatively low in 2009 at Rs 226 on average, but they rise to Rs 813 in 2012 and 1,056 in 2008.

In terms of labor costs, we note that lthey increase over time, even with adjustments for inflation. Overall, wages in our study area seem to be higher than in AEK's, as can be seen in Tble 4, leading to higher labor costs in all three survey rounds.

Finally, given these figures, we are ready to compute profits and rates of return (RoRs), with and without considering labor costs, and we report these in the penultimate panel of Table 5. AEK's rationale for excluding labor costs is that they do not have information on multitasking and can therefore not assess its importance. Since multitasking might reduce the effective costs of labor, they also report RoR estimates excluding this cost item. For comparability, we do the same. 
We further report RoRs where we exclude other losses when the animal fell ill (a cost item AEK do not account for) and use AEK's labor cost estimates. These RoRs are reported in the bottom panel of Table 5 . We report both average and median RoR, the former comparing to the 2013 AEK working paper version and the latter to the 2016 version published in this journal. ${ }^{11}$

Concentrating on median figures, what we see is that our figures for 2012 are very similar to those reported by AEK, who report a positive return of $17 \%$ when ignoring labor costs and one of $-65 \%$ when accounting for labor costs Our estimates lie at $15 \%$ without and at $-50 \%$ with labor costs, and are hence remarkably similar. The same holds for the $95 \%$ confidence intervals. For our reported median values the confidence intervals are $[2 ; 33]$ and $[-60 ;-35]$ respectively. AEKs reported confidence interval for the return of $17 \%$ without accounting for labor is [3.5;26]. Our estimates in 2009 are lower, at -13\% (confidence interval $[-27 ;-2]$ ) with labor costs and $-106 \%$ (confidence interval $[-126 ;-89]$ ) without.

When we consider 2008, however, the picture is very different. When ignoring labor costs, the return on holding a cow is a very large $83 \%$ (confidence interval [75;90]). When factoring in our estimates of labor costs, this is reduced to a still very respectable $13 \%$ (confidence interval [4;21]). Without the additional losses from sick animals and with AEK's assumptions on depreciation and labor costs, these even increase to $91 \%$ without and $27 \%$ with labor costs (confidence intervals of $[83 ; 98]$ and $[20 ; 35]$ respectively.

When considering rates of return for cows (presented in Table 6), we note that our sample of cows is smaller than that of buffaloes, reflecting the fact that conditions in Anantapur are less favorable for cows than for buffaloes. We see this reflected in the returns being lower and costs higher on average than for buffaloes. However, the picture of variation in returns over time holds also for our sample of cows. In the two latter survey years, we find - as do AEK - negative returns for cows independent of whether labor costs are included or not. In

\footnotetext{
${ }^{11}$ Tables B1 and B2 in Appendix B show the rates of return concentrating on households that were not BASIX clients at the time of the first survey round, serving as a robustness check, as discussed in Section 2.
} 
2012, the median return estimate is $-5 \%$ without labor costs in our sample, the same as in in AEK's.

\section{[TABLE6 ABOUT HERE]}

However, in 2008 we again see a sizable positive returns at $66 \%$ excluding costs of labor and $-17 \%$ including them. Making the estimates again more comparable to AEKs, these values increase to $71 \%$ and $4 \%$ respectively.

We provide a picture of the distribution of rates of return in the three survey years for buffaloes and cows in Figure D1 of Appendix D. The figure excludes labor costs.

What makes these years so different? The answer is simple and predictable in an economy such as that of Anantapur, which is so dependent on rain. 2008 was a year of abundant rain at the right time of the year, while 2009 was officially declared a year of drought; 2012 also faced large challenges due to below average rain spells. In such drought years, fodder is scarce and expensive, cattle do not eat much and, as a consequence, they produce less milk over a shorter period. Also, insemination becomes more difficult, which reduces the likelihood of any milk production, and animals are more prone to diseases and death. The result is a negative and (in the long run unsustainable) return - especially for cows. Buffaloes are slightly better adapted to these conditions, which is reflected in positive returns in two out of our three periods (as long as labor costs are not accounted for). Importantly though, the returns experienced in 2009 and 2012 are not long run returns: in a year such as 2008, when rains were better than usual, the returns on both cows and buffaloes were healthily positive.

\section{Conclusions}

In this note, we have shown that the proof against the central tenets of capitalism does not hold, given a closer analysis of data on the return on cows and buffaloes in India. While 
it is true that in specific years cows and buffaloes yield negative returns, the same is also true of many equities traded in the stock market. We show that in other years the return on cows and buffaloes can be positive. This is obviously not a proof that the behaviour of Indian farmers about holding livestock is optimal. Neither does it mean that cows and buffaloes may not be held for many other reasons, beside the economic return that they provide. These reasons may include cultural and religious factors, as well as more complex economic incentives related to different types of intertemporal and interpersonal trade. But the economic return can also be a good reason to own a cow or a buffaloe. 


\section{References}

Acemoglu, Daron, and James Robinson. 2013. "Cows, Capitalism and Social Embeddedness." http://whynationsfail.com/blog/2013/10/23/cows-capitalism-and-social-embeddedness.html (last accessed March 25, 2016).

Anagol, Santosh, Alvin Etang, and Dean Karlan. 2013. "Continued Existence of Cows Disproves Central Tenets of Capitalism?", NBER Working Paper no. 19437, National Bureau of Economic Research, Cambridge, MA.

- 2014. "Continued Existence of Cows Disproves Central Tenets of Capitalism?", Working Paper, unpublished, http://assets.wharton.upenn.edu/ anagol/Cows-2014-12-10.pdf (last accessed March 25 2016).

- 2016. "Continued Existence of Cows Disproves Central Tenets of Capitalism?" Economic Development and Cultural Change. Forthcoming.

Attanasio, Orazio, and Britta Augsburg. 2016. "Subjective Expectations and Income Processes in Rural India." Economia. Forthcoming.

Augsburg, Britta. 2009. "Microfinance - Greater Good or Lesser Evil?" PhD thesis, Maastricht Graduate School of Governance, University of Maastricht.

- 2011. "Livestock for the Poor: Under What Conditions?" IFS Working Paper no. W11/21, The Institute for Fiscal Studies, London.

Gehrke, Esther, and Michael Grimm. 2014. "Do Cows Have Negative Returns? The Evidence Revisited." IZA Discussion Paper no. 8525, Institute for the Study of Labor, Bonn.

Rosenzweig, Mark R., and Christopher Udry. 2013. "Forecasting Profitability." Economic Growth Center Discussion Paper no. 1029, Yale University.

Rosenzweig, Mark R., and Wolpin, Kenneth I., 1989. "Credit Market Constraints, Con-

sumption Smoothing and the Accumulation of Durable Production Assets in Low-Income 
Countries: Investments in Bullocks in India," Bulletins 7487, University of Minnesota, Economic Development Center. 


\section{Appendix}

Appendix A

[TABLE A1 ABOUT HERE]

[TABLE A2 ABOUT HERE] 


\section{Appendix B}

[TABLE B1 ABOUT HERE]

[TABLE B2 ABOUT HERE] 
Appendix C

[TABLE C1 ABOUT HERE] 
Appendix D

[FIGURE D1 ABOUT HERE] 


\section{Tables - main text}

Table 1: Animals owned by households

\begin{tabular}{|c|c|c|c|c|c|c|}
\hline & \multicolumn{2}{|c|}{ R1-2008 } & \multicolumn{2}{|c|}{$\mathrm{R} 2-2009$} & \multicolumn{2}{|c|}{ R3-2012 } \\
\hline & Obs. & $\%$ & Obs. & $\%$ & Obs. & $\%$ \\
\hline HHs that own livestock & 638 & 61.3 & 411 & 43.2 & 316 & 35.7 \\
\hline HHs that own female livestock (conditional) & 585 & 91.7 & 379 & 92.2 & 295 & 93.4 \\
\hline HHs that own only buffaloes (conditional) & 463 & 72.6 & 257 & 62.5 & 150 & 47.5 \\
\hline HHs that own only cows (conditional) & 69 & 10.8 & 60 & 14.6 & 37 & 11.7 \\
\hline No of livestock owned by HH (if owned) & 3.53 & & 3.93 & & 4.66 & \\
\hline No of female livestock owned by HH (if owned) & 1.74 & & 2.42 & & 2.66 & \\
\hline
\end{tabular}

Note: The table shows descriptive statistics on livestock ownership in the three survey rounds. "Obs." is short for number of observations. Data: Own survey $(2008,2009,2012)$. 


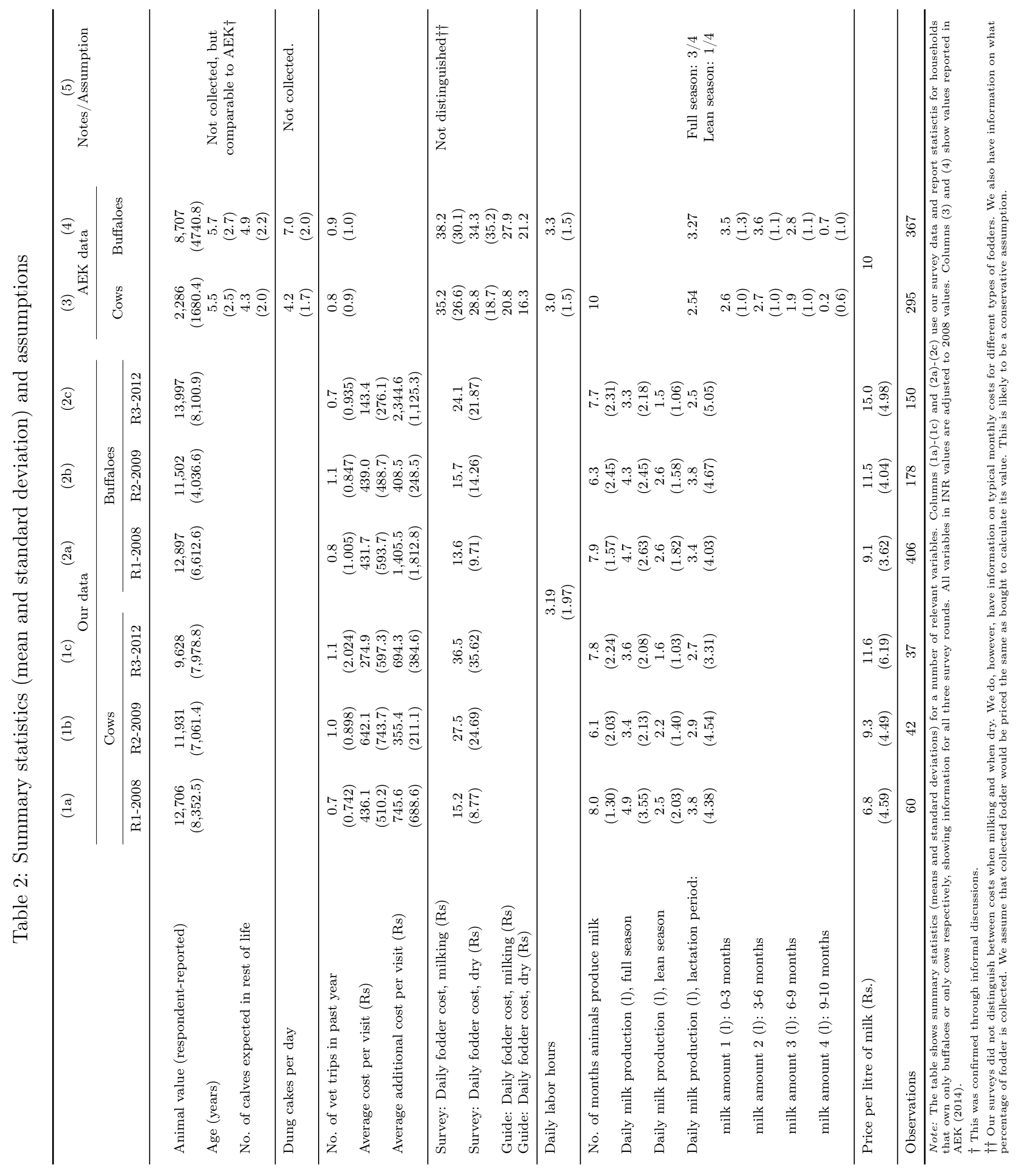


Table 3: Average income from dairy (typical and last year's

\begin{tabular}{lccc}
\hline & R1-2008 & R2-2009 & R3-2012 \\
\cline { 2 - 4 } & \multicolumn{3}{c}{ Cows (means, Rs) } \\
\hline Total last year (income section) & 13,574 & 3,345 & 8,579 \\
Typical year (monthly from livestock section * 12) & 11,167 & 10,204 & 14,695 \\
& \multicolumn{3}{c}{ Buffalos (mean) } \\
\cline { 2 - 4 } Total last year (income section) & \multicolumn{3}{c}{5,048} \\
Typical year (monthly from livestock section * 12) & 11,040 & 9,598 & 14,782 \\
\hline
\end{tabular}

Note: The table shows summary statistics (means) for total income from dairy in the year previous to the survey round (which includes income from selling milk as well as other by-products, such as dung) and typical income from selling milk (i.e. excluding income from other by-products). Values in 2009 and 2012 are adjusted for inflation. Data: Own survey $(2008,2009,2012)$. 
Table 4: Costs per hour of labor in Rupees

\begin{tabular}{|c|c|c|c|c|c|}
\hline & & & $\begin{array}{l}\text { Daily } \\
\text { wage }\end{array}$ & $\begin{array}{c}\text { Hourly } \\
\text { wage ( } 8 \mathrm{hrs})\end{array}$ & $\begin{array}{c}\text { Average } \\
\text { wage }\end{array}$ \\
\hline \multirow[t]{3}{*}{ R1 - } & \multirow[t]{3}{*}{2008} & male: & 90 & 9.375 & \multirow{3}{*}{6.6} \\
\hline & & female: & 60 & 9.010 & \\
\hline & & minor (calculated): & 30 & 3.75 & \\
\hline \multirow[t]{3}{*}{ R2 - } & \multirow[t]{3}{*}{2009} & male: & 109 & 1196 & \multirow{3}{*}{8.4} \\
\hline & & female: & 83 & 11.90 & \\
\hline & & minor (calculated): & 39 & 4.78 & \\
\hline \multirow[t]{4}{*}{ R3 - } & \multirow[t]{4}{*}{2012} & male: & 120 & 123 & \multirow{4}{*}{7.9} \\
\hline & & female: & 77 & & \\
\hline & & minor: & 63 & 7.92 & \\
\hline & & minor (calculated): & 28 & 3.52 & \\
\hline \multirow[t]{2}{*}{ AEK } & \multirow[t]{2}{*}{2007} & adult (male and female): & 64 & 8 & \multirow{2}{*}{5.6} \\
\hline & & minor: & 26 & 3 & \\
\hline
\end{tabular}

Note: For our survey, unless labeled '(calculated)', the average village daily wage is reported. 2009, 2012 and AEK numbers are adjusted for inflation. Hourly wages are calculated based on the assumption of an eight hour working days. Data: Own survey $(2008,2009,2012)$ and AEK values. 
Table 5: Rates of return - buffaloes

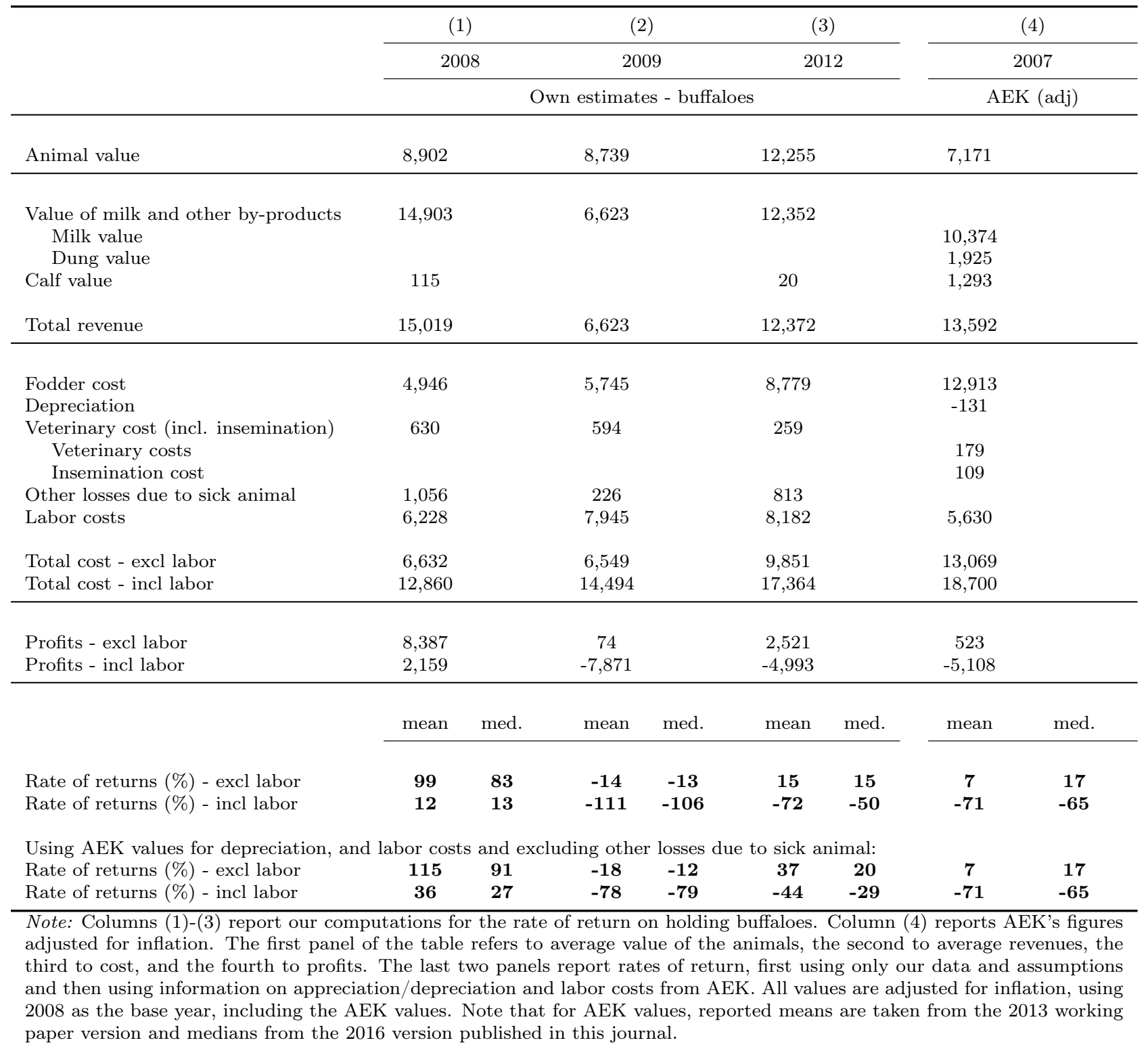


Table 6: Rates of return - cows

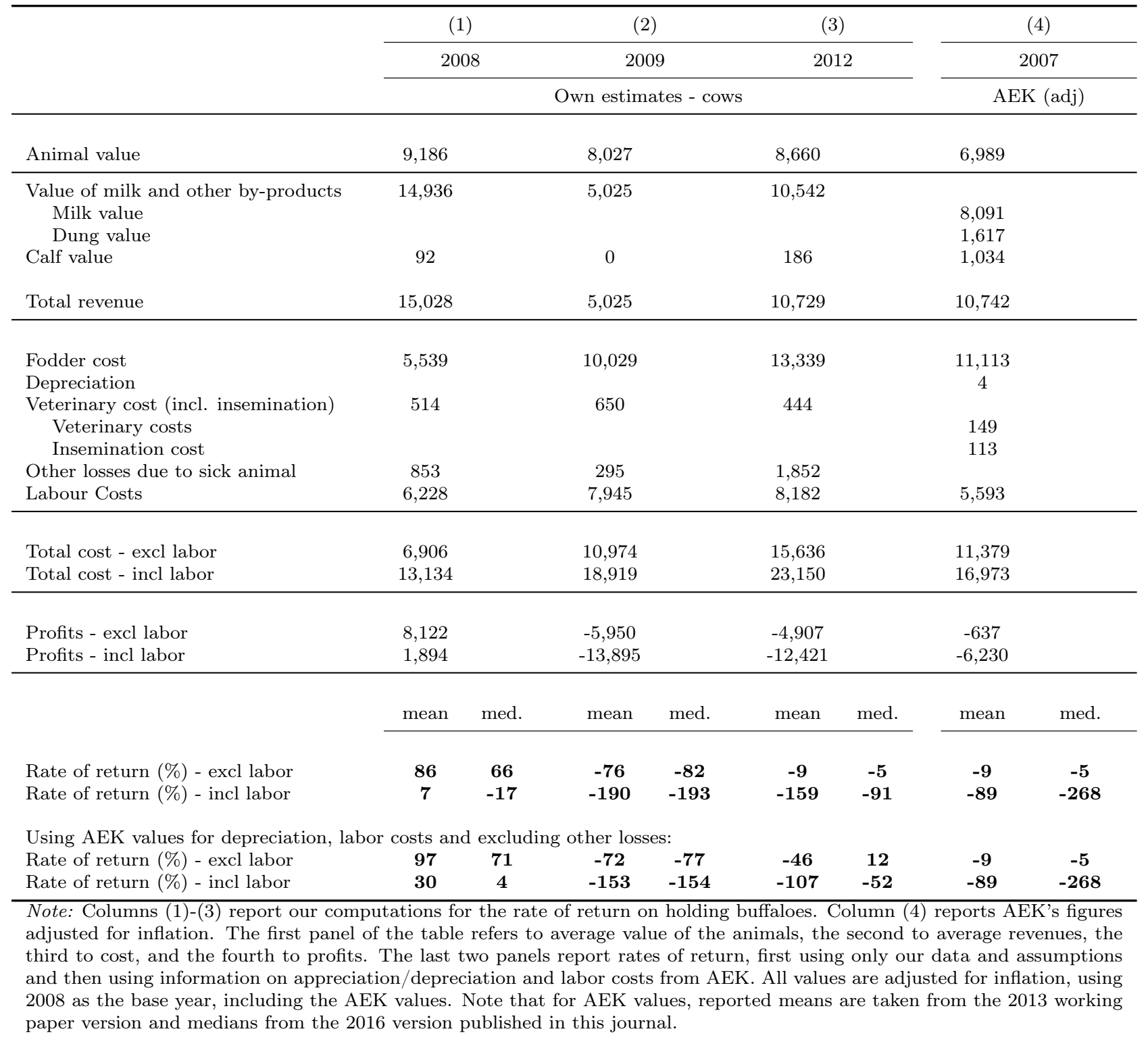




\section{Tables - appendix}

Table A1: Characteristics of cattle-owning households, 2008

\begin{tabular}{lllll}
\hline Variable & & \multicolumn{3}{c}{2008 sample } \\
\cline { 2 - 5 } & & mean & med. & s.d. \\
\hline Household head & Age & 44.3 & 43.0 & 11.6 \\
& Male & 0.92 & 1.00 & 0.27 \\
& No formal education & 0.62 & 1.00 & 0.49 \\
& Some primary education & 0.10 & 0.00 & 0.30 \\
\hline \multirow{2}{*}{ Household composition } & No of household members & 4.82 & 5.00 & 1.69 \\
& No. of females & 2.33 & 2.00 & 1.21 \\
& No. of kids 0-5 yrs & 0.36 & 0.00 & 0.65 \\
& No. of kids 6-10 yrs & 0.48 & 0.00 & 0.73 \\
& No. of kids 11-16 yrs & 0.66 & 0.00 & 0.83 \\
& No. of elderly (>63 yrs) & 0.16 & 0.00 & 0.43 \\
\hline Caste of household & Scheduled caste & 0.10 & 0.00 & 0.30 \\
& Scheduled tribe & 0.04 & 0.00 & 0.19 \\
& Backward & 0.44 & 0.00 & 0.50 \\
& Forward & 0.37 & 0.00 & 0.48 \\
\hline Primary activity of household & Farmer & 0.34 & 0.00 & 0.47 \\
& Self-employed & 0.03 & 0.00 & 0.17 \\
& Agricultural labor & 0.58 & 1.00 & 0.49 \\
\hline
\end{tabular}

Notes

The table shows means, medians (med) and standard deviations (s.d.) or our sample. Education, caste and primary activity variables are expressed as fractions.

Data source: Own survey, first survey round, 2008. 
Table A2: Animals owned by households classified as non-BASIX in 2008

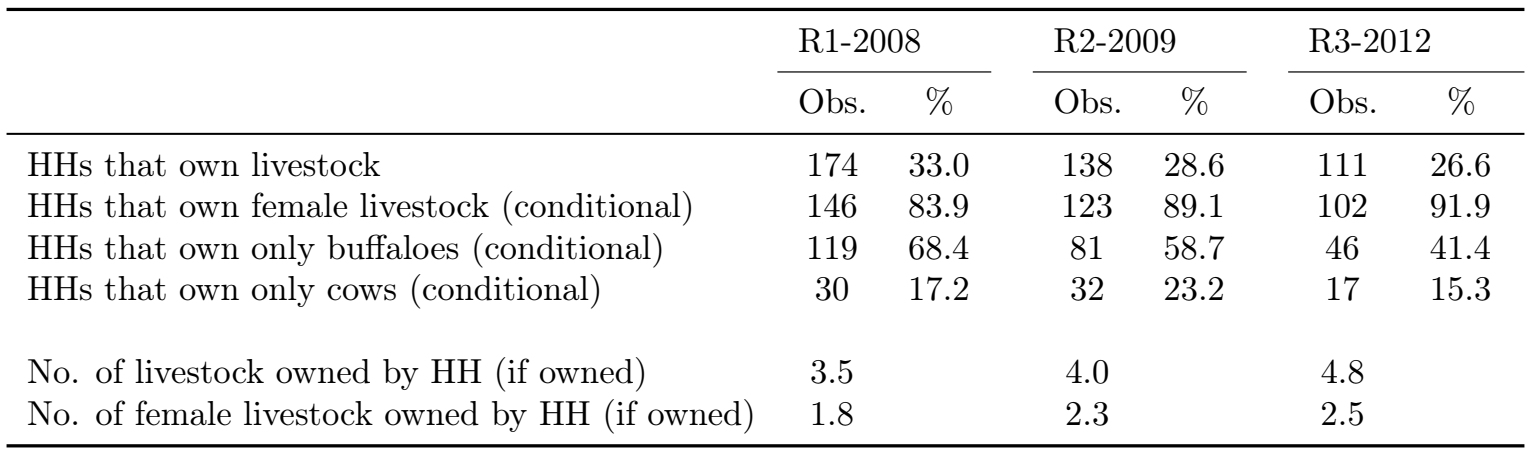

Note: The Table shows descriptive statistics on livestock ownership in the three survey rounds. 'Obs.' is short for number of observations. Data: Own survey $(2008,2009,2012)$. 
Table B1: Rates of return - buffaloes, including and excluding BASIX clients

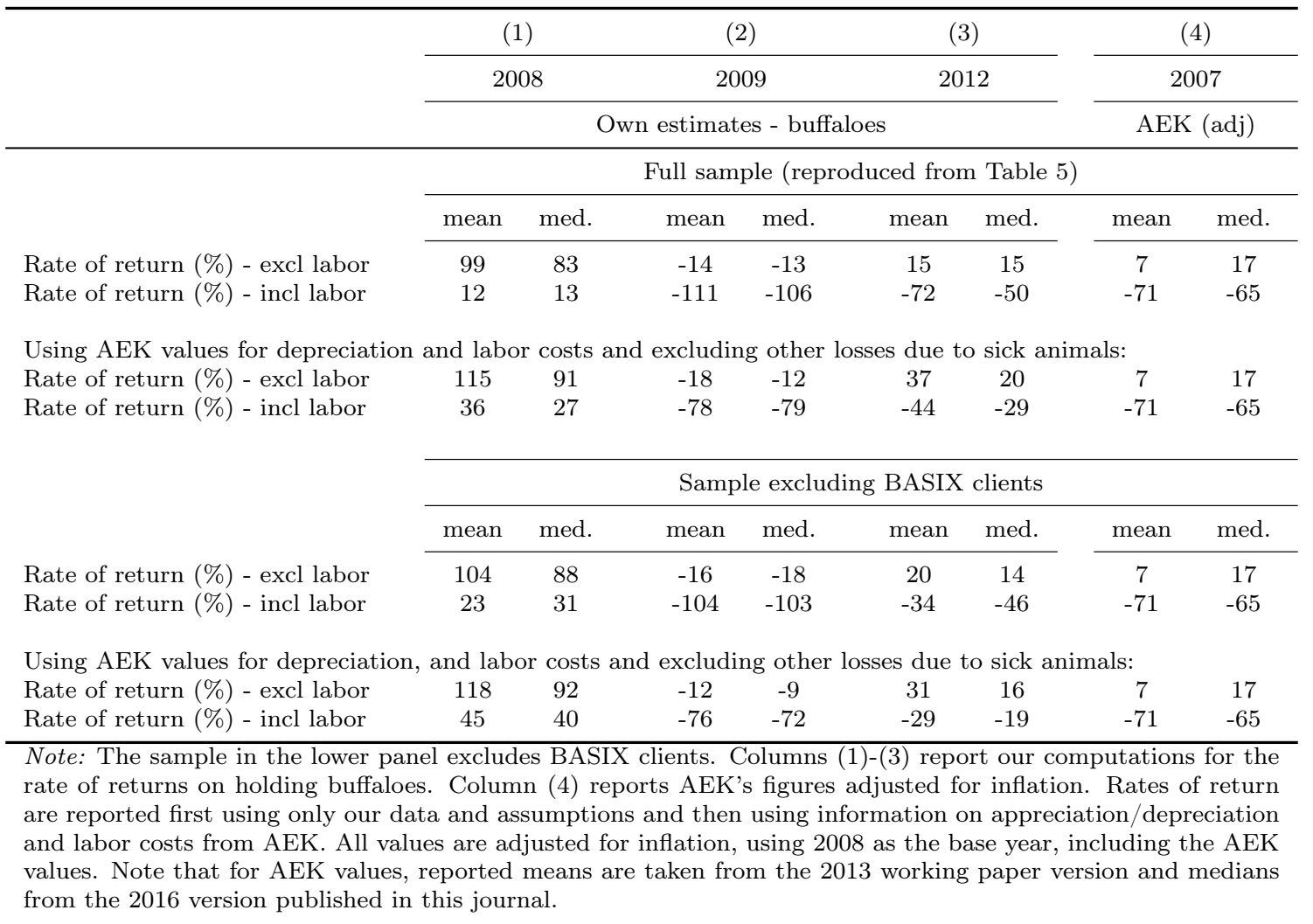


Table B2: Rates of return - cows, including and excluding BASIX customers

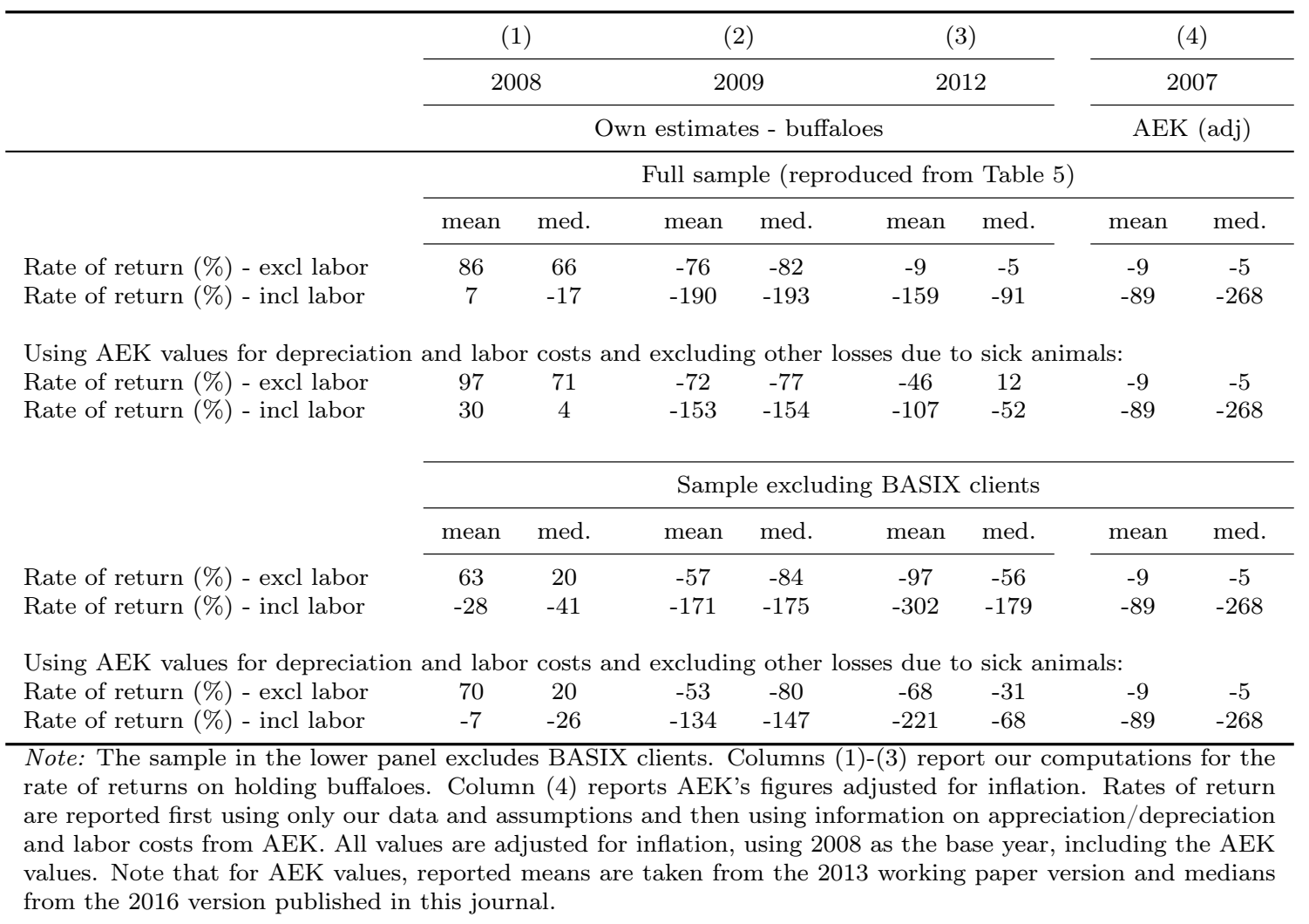


Table C1: Anantapur district rainfall

\begin{tabular}{|c|c|c|c|c|c|c|c|c|c|c|c|c|c|}
\hline & & Jan & Feb & Mar & Apr & May & Jun & Jul & Aug & Sep & Oct & Nov & Dec \\
\hline $\begin{array}{l}\text { Actual } \\
\% \text { of normal }\end{array}$ & 2007 & $\begin{array}{c}0 \\
0 \%\end{array}$ & $\begin{array}{c}0 \\
0 \%\end{array}$ & $\begin{array}{c}0 \\
0 \%\end{array}$ & $\begin{array}{c}19.8 \\
165 \%\end{array}$ & $\begin{array}{c}65.5 \\
164 \%\end{array}$ & $\begin{array}{l}150.7 \\
235 \%\end{array}$ & $\begin{array}{c}73.3 \\
109 \%\end{array}$ & $\begin{array}{c}108 \\
121 \%\end{array}$ & $\begin{array}{l}197.4 \\
167 \%\end{array}$ & $\begin{array}{l}94.6 \\
85 \%\end{array}$ & $\begin{array}{c}9.4 \\
27 \%\end{array}$ & $\begin{array}{c}17.4 \\
174 \%\end{array}$ \\
\hline $\begin{array}{l}\text { Actual } \\
\% \text { of normal }\end{array}$ & 2008 & $\begin{array}{c}0 \\
0 \%\end{array}$ & $\begin{array}{c}21.1 \\
2110 \%\end{array}$ & $\begin{array}{c}85.9 \\
2863 \%\end{array}$ & $\begin{array}{l}0.4 \\
3 \%\end{array}$ & $\begin{array}{c}57.8 \\
145 \%\end{array}$ & $\begin{array}{l}62.5 \\
98 \%\end{array}$ & $\begin{array}{c}87.4 \\
130 \%\end{array}$ & $\begin{array}{l}108.6 \\
122 \%\end{array}$ & $\begin{array}{l}211.2 \\
179 \%\end{array}$ & $\begin{array}{l}111.9 \\
101 \%\end{array}$ & $\begin{array}{c}48.6 \\
139 \%\end{array}$ & $\begin{array}{l}0.5 \\
5 \%\end{array}$ \\
\hline $\begin{array}{l}\text { Actual } \\
\% \text { of normal }\end{array}$ & 2009 & $\begin{array}{c}0.5 \\
25 \%\end{array}$ & $\begin{array}{c}0 \\
0 \%\end{array}$ & $\begin{array}{c}6.7 \\
223 \%\end{array}$ & $\begin{array}{c}4.6 \\
38 \%\end{array}$ & $\begin{array}{c}71.4 \\
179 \%\end{array}$ & $\begin{array}{l}55.3 \\
86 \%\end{array}$ & $\begin{array}{c}9 \\
13 \%\end{array}$ & $\begin{array}{l}102.8 \\
116 \%\end{array}$ & $\begin{array}{l}191.1 \\
162 \%\end{array}$ & $\begin{array}{l}61.5 \\
55 \%\end{array}$ & $\begin{array}{c}67.1 \\
192 \%\end{array}$ & $\begin{array}{c}4 \\
40 \%\end{array}$ \\
\hline $\begin{array}{l}\text { Actual } \\
\% \text { of normal }\end{array}$ & 2010 & $\begin{array}{c}4.4 \\
220 \%\end{array}$ & $\begin{array}{c}1 \\
100 \%\end{array}$ & $\begin{array}{c}3 \\
100 \%\end{array}$ & $\begin{array}{c}33.8 \\
282 \%\end{array}$ & $\begin{array}{c}83.3 \\
208 \%\end{array}$ & $\begin{array}{c}77.2 \\
121 \%\end{array}$ & $\begin{array}{l}107.6 \\
161 \%\end{array}$ & $\begin{array}{l}149.7 \\
168 \%\end{array}$ & $\begin{array}{l}68.8 \\
58 \%\end{array}$ & $\begin{array}{l}72.2 \\
65 \%\end{array}$ & $\begin{array}{l}150.8 \\
431 \%\end{array}$ & $\begin{array}{l}0.6 \\
6 \%\end{array}$ \\
\hline $\begin{array}{l}\text { Actual } \\
\% \text { of normal }\end{array}$ & 2011 & $\begin{array}{c}0 \\
0 \%\end{array}$ & $\begin{array}{c}0.6 \\
60 \%\end{array}$ & $\begin{array}{c}5.4 \\
180 \%\end{array}$ & $\begin{array}{c}33.3 \\
278 \%\end{array}$ & $\begin{array}{c}57.6 \\
144 \%\end{array}$ & $\begin{array}{l}38.9 \\
61 \%\end{array}$ & $\begin{array}{c}85.3 \\
127 \%\end{array}$ & $\begin{array}{l}112.5 \\
126 \%\end{array}$ & $\begin{array}{l}26.1 \\
22 \%\end{array}$ & $\begin{array}{l}88.9 \\
80 \%\end{array}$ & $\begin{array}{l}22.6 \\
65 \%\end{array}$ & $\begin{array}{c}3 \\
30 \%\end{array}$ \\
\hline $\begin{array}{l}\text { Actual } \\
\% \text { of normal }\end{array}$ & 2012 & $\begin{array}{c}0.6 \\
30 \%\end{array}$ & $\begin{array}{c}0 \\
0 \%\end{array}$ & $\begin{array}{c}0 \\
0 \%\end{array}$ & $\begin{array}{c}33 \\
275 \%\end{array}$ & & & & & & & & \\
\hline
\end{tabular}

Source: http://www.imd.gov.in/section/hydro/distrainfall/webrain/andhra/anantapur.txt and http://archive.is/be3q, last accessed on March 30th 2014), last accessed on March 302014.

Note: "Actual" indicates the actual rainfal reported in the given month and year. "\% of normal" indicates the percentage of actual rain to normal long-run average rainfall in the given month and year. Numbers in bold are months during which data colllection took place. 


\section{Figures}

Figure D1: Distributions of rates of return fo buffaloes (left) and cows (right), valuing labor at zero, 2008, 2009 and 2012
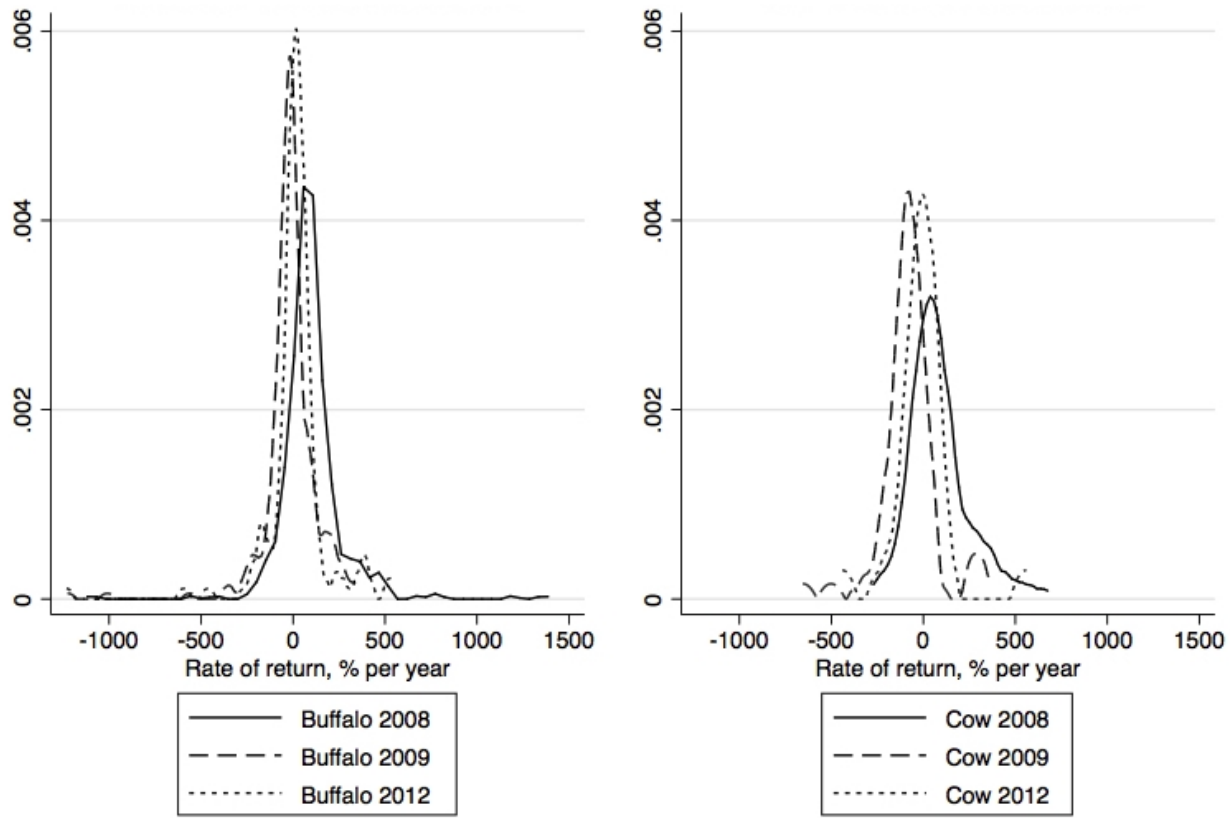